\title{
Generalized Anxiety Disorder
}

National Cancer Institute

\section{Source}

National Cancer Institute. Generalized Anxiety Disorder. NCI Thesaurus. Code C92622.

An anxiety disorder characterized by excessive and difficult-to-control worry about a number of life situations. The worry is accompanied by restlessness, fatigue, inability to concentrate, irritability, muscle tension, and/or sleep disturbance and lasts for at least 6 months. 